\title{
Kinetics of Ion-Molecule Reactions
}




\section{NATO ADVANCED STUDY INSTITUTES SERIES}

A series of edited volumes comprising multifaceted studies of contemporary scientific issues by some of the best scientific minds in the world, assembled in cooperation with NATO Scientific Affairs Division.

Series B: Physics

\section{RECENT VOLUMES IN THIS SERIES}

Volume 32 - Electron and Ion Spectroscopy of Solids edited by L. Fiermans, J. Vennik, and W. Dekeyser

Volume 33 - Microscopic Structure and Dynamics of Liquids edited by J. Dupuy and A. J. Dianoux

Volume 34 - Path Integrals and Their Applications in Quantum, Statistical, and Solid State Physics edited by George J. Papadopoulos and J. T. Devreese

Volume 35 - Correlation Functions and Quasiparticle Interactions in Condensed Matter edited by J. Woods Halley

Volume 36 - Strongly Coupled Plasmas edited by Gabor Kalman

Volume 37 - Coherence in Spectroscopy and Modern Physics edited by F. T. Arecchi, R. Bonifacio, and M. O. Scully

Volume 38 - Theoretical Methods in Medium-Energy and Heavy-Ion Physics edited by K. W. McVoy and W. A. Friedman

Volume 39 - Hadron Structure and Lepton-Hadron Interactions - Cargèse 1977 edited by Maurice Lévy, Jean-Louis Basdevant, David Speiser, Jacques Weyers, Raymond Gastmans, and Jean Zinn-Justin

Volume 40 - Kinetics of Ion-Molecule Reactions edited by Pierre Ausloos

Volume 41 - Fiber and Integrated Optics edited by D.B. Ostrowsky

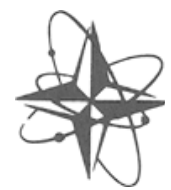

The series is published by an international board of publishers in conjunction with NATO Scientific Affairs Division
A Life Sciences
B Physics
C Mathematical and Physical Sciences
D Behavioral and
Social Sciences
E Applied Sciences

Plenum Publishing Corporation

New York and London

D. Reidel Publishing Company

Dordrecht and Boston

Sijthoff International Publishing Company Leiden

Noordhoff International Publishing

Leiden 


\section{Kinetics of Ion-Molecule Reactions}

Edited by Pierre Ausloos

United States Department of Commerce National Bureau of Standards

Washington, D.C.

\section{PLENUM PRESS • NEW YORK AND LONDON}

Published in cooperation with NATO Scientific Affairs Division 
Library of Congress Cataloging in Publication Data

Nato Advanced Study Institute on Kinetics of Ion-Molecule Reactions, La Baule, 1978.

Kinetics of ion-molecule reactions.

(Nato advanced study institutes series: Series B, physics; v. 40)

Includes bibliographical references and index.

1. Chemical reaction, Conditions and laws of-Congresses. 2. Ions-Congresses. 3. Molecules-Congresses. I. Ausloos, Pierre J. II. Title. III. Series.

QD501.N37 1978 $541^{\prime} .39$

79-367

ISBN-13: 978-1-4613-2933-6

e-ISBN-13: 978-1-4613-2931-2

DOI: $10.1007 / 978-1-4613-2931-2$

Proceedings of the NATO Advanced Study Institute on Kinetics of Ion-Molecule Reactions held at La Baule, France, September 4-15, 1978

() 1979 Plenum Press, New York

Softcover reprint of the hardcover 1st edition 1979

A Division of Plenum Publishing Corporation

227 West 17th Street, New York, N.Y. 10011

All rights reserved

No part of this book may be reproduced, stored in a retrieval system, or transmitted, in any form or by any means, electronic, mechanical, photocopying, microfilming, recording, or otherwise, without written permission from the Publisher 


\section{Preface}

The investigation of the elementary reactions of reactive intermediate species began about half a centruy ago with the advent of free radical kinetics as an active area of chemical research. In spite of the relatively greater ease of detection of a species carrying an electrical charge, and the fact that organic chemists had for decades postulated mechanisms involving ionic intermediates, the systematic study of the elementary reactions of ions was delayed for more than twenty years after the first beginnings of free radical kinetics. Even at this writing, in 1978, the word "kinetics" is considered by many chemists to be synomomous with "kinetics of neutral species".

Yet in spite of the relatively late start and separation from the mainstream of kinetics, the field of ion physics and chemistry is fluorishing, and growing at an ever faster pace. Instrumentalists devise ever more sophisticated apparatuses with capabilities of delving into nearly every aspect of the interactions between ions and molecules. Even satellites orbiting the earth are now being used effectively to determine rate coefficients of ionospheric ion-neutral reactions, some of which can not as yet be measured in the laboratory.

This book contains discussions of some of these new experimental approaches and the resulting knowledge which has been acquired since the earlier 1974 NATO Advanced Study Institute on Interactions between Ions and Molecules, which was held in Biarritz, France. Besides the more fundamental aspects of ion kinetics and the characterization of ions with regard to structure and energy, ionic processes occurring in interstellar space, the earth's atmosphere, lasers, and combustion, are discussed here. In addition, readers will find chapters describing nucleation phenomena and the relationships between ionic processes occurring in the gas and liquid phases.

I would like to express my appreciation to everyone who contributed to the success of the NATO Advanced Study Institute on Kinetics of Ion-Molecule Reactions held at La Baule, France, in 
September, 1978. This includes not only all of the lecturers, those who contributed to the discussion panels, and those who chaired the sessions, but, just as important, all of those in attendance whose interest and enthusiasm contributed to the stimulating atmosphere of the Institute. I would also like to give recognition to the efforts of the members of the Organizing Committee Rose Marx, Sharon Lias, Keith Jennings, Paul Kebarle, Eldon Ferguson, and especially Tom Govers, who was largely responsible for the smooth functioning of the physical details of the meeting. On behalf of all participants, I would like to thank the Scientific Affairs Division of the North Atlantic Treaty Organization without whose financial assistance the occurrence of such a constructive summer school would not have been possible. I personally would like particularly to acknowledge the moral support supplied by the secretary of the Scientific Affairs Division, Dr. Tilo Kester. We also thank the National Science Foundation of the U.S.A. for travel grants.

P. Ausloos

Washington, DC

November, 1978 


\section{Contents}

Potential Energy Surfaces for Ion-Molecule

Reactions Panel Discussion Led by

Joyce J. Kaufman . . . . . . . . . . . . •

Ion-Dipole Collisions: Recent Theoretical

Advances

Walter J. Chesnavich, Timothy Su, and

Michael T. Bowers . . . . . . . . . . .

Ion-Molecule Collisions: Theory and Experiment

Pane1 Discussion Led by Douglas P. Ridge . . . .

Ion-Molecule Collision Complexes

Panel Discussion Led by Cornelius E. Klots . . . .

Molecular Beam Studies of Ion-Molecule

Reactions

W. Ronald Gentry . . . . . . . . . . . . .

Charge Transfers at Thermal Energies: Energy

Disposal and Reaction Mechanisms

R. Marx ....................

Energy Dependences of Ion-Neutral Reactions

Studied in Drift Tubes

Daniel Lee Albritton ...............

Internal Energy Partitioning

Panel Discussion Led by J. J. Leventha1 . . . .

Factors Influencing Thermal Ion-Molecule Rate

Constants

John I. Brauman . . . . . . . . . . . .

Mechanistic Aspects of Ion-Molecule Reactions

N. M. M. Nibbering . . . . . . . . . . . 
Intramolecular Selectivity, Stereochemical and

Steric Aspects of Ion-Molecule Reactions

Fulvio Cacace . . . . . . . . . . . . .

Thermochemistry of Polyatomic Cations

Sharon G. Lias . . . . . . . . . . .

Equilibrium Studies of Negative Ion-Molecule

Reactions

Robert T. McIver, Jr. . . . . . . . . .

Proton Transfer Reactions in the Gas and

Solution Phase

Robert W. Taft

Studies of Ion Clusters: Relationship to

Understanding Nucleation and Solvation

Phenomena

A. W. Castleman, Jr. . . . . . . . . .

Chemical Ionization in Flames

D. K. Bohme . . . . . . . . . . . .

Ion-Molecule Reactions in Low Temperature

Plasmas: Formation of Interstellar

Species

David Smith and Nigel G. Adams . . . . . . .

Ion-Molecule Reactions in the Atmosphere

Eldon E. Ferguson . . . . . . . . . . . .

Ion-Molecule Processes in Lasers

James B. Laudenslager . . . . . . . . . .

Decay Processes of the Lowest Excited

Electronic States of Polyatomic Radial

Cations

J. P. Maier . . . . . . . . . . . . .

Ion Photodissociation

Robert Dunbar . . . . . . . . . . . .

New Instrumentation for the Investigation of

Ion-Molecule Reactions

Panel Discussion Led by John R. Eyler

(Prepared by Ben S. Freiser) . . . . . . .

Index . . . . . . . . . . . . . . . . 